\title{
Renée Vivien, tradutora de Safo
}

Letticia Batista Rodrigues Leite *

Resumo: O objetivo deste artigo é apresentar e comentar, de forma breve, as traduções/versões francesas de duas composições atribuídas à poeta Safo de Lesbos (VII-VI a.C.), feitas por Renée Vivien (1877-1909). O enfoque não será posto na avaliação da qualidade literária dos textos em francês em comparação com os textos originais, em grego, mas nas motivações que levaram essa autora a traduzir os poemas sáficos, assim como na sua escolha explícita em afirmar o homoerotismo poético, expresso no feminino, que pode ser lido nesses fragmentos e que, a contragosto ou não, impôs-se, em alguma medida, à crítica que se dedicou a comentá-los como uma questão incontornável.

Palavras-Chave: Renée Vivien; Safo de Lesbos; tradução.

\section{Renée Vurien, Sappho'stranslator}

Abstract: The purpose of this article is to present and to comment, briefly, the French translation / versions made by Renée Vivien (1877-1909) of two compositions attributed to the poet Sappho of Lesbos (VII-VI BCE). The aim here is not to discuss the literary value of the French translation, in parallel to the Greek text, but the reasons why this author decided to translate the Sappho's poems and her explicit choice in asserting the poetical homoeroticism, expressed in the feminine, which can be ready in these fragments and that, like it or not, impose itself upon the critic reviews as if it is an unavoidable question.

Keywords: Renée Vivien; Sappho of Lesbos; translation.

* Doutora em História pela Université Paris 1 Panthéon-Sorbonne (Bolsista CAPES).

Contato: letticiabrl@gmail.com 
Até o presente, muitos foram os trabalhos que se propuseram a estudar a recepção dos fragmentos textuais e da figura de Safo, nos mais diversos contextos e suportes artísticos (DEJEAN, 1989; DEMARCHI, 2013; GREENE, 1996). Desse conjunto, interessa-me aqui destacar aqueles que ressaltaram a importância simbólica da figura de Safo, assim como a influência dos fragmentos de composições da poeta como fontes de inspiração para as mulheres escritoras e, em particular, para as lésbicas escritoras (GUBAR, 1984; MARKS, 1979; SNYDER, 1997). Se muitos desses trabalhos buscaram destacar as especificidades que estariam presentes na poética sáfica, assim como de outros "escritos femininos" (SKINNER, 1993), outros se opuseram à ideia de uma escrita "especificamente feminina" - tida como essencialista -, valendo-se amplamente do vulto da poeta de Lesbos e de sua poética como fontes de autoridade e de inspiração artística, elementos dos quais, em seus escritos, propuseram usos abertamente político-feministas (WITTIG, 2004 [1973], 2007 [1982]; WITTIG; ZEIG, 2001 [1976]; ÉCARNOT, 2002).

Talvez menos numerosas, porém, foram as análises dedicadas especificamente às traduções, já publicadas nos mais diversos idiomas, dos cerca de 200 fragmentos atribuídos à poeta de Lesbos que nos chegaram ${ }^{1}$. Nesse sentido, destaque deve ser dado ao estudo das traduções em língua inglesa, feito por Yopie Prins, professora e pesquisadora da Universidade de Michigan, em um artigo publicado no ano de 1997, intitulado "Sappho's Afterlife in Translation". Vale mencionar ainda, em especial para o assunto que aqui me interessa tratar, um artigo recentemente publicado por Jacqueline Fabre-Serris, professora e pesquisadora da Universidade de Lille 3: "Anne Dacier (1681), Renée Vivien (1903): Or What Does it mean for a Woman to Translate Sappho?", de 2016; nele, a autora faz uma apreciação das traduções de Safo feitas por duas mulheres: Anne Dacier e Renée Vivien, destacando sobretudo a importância da figura de Safo para essas duas mulheres que atuaram em contextos intelectuais e literários predominantemente masculinos.

O objetivo deste artigo é, pois, apresentar e comentar a tradução/versão de dois poemas de Safo, assim como do paratexto que as precede, feitas por Renée Vivien. O propósito aqui é ressaltar as motivações que levaram esta última a traduzir os poemas sáficos, não de avaliar a qualidade literária das suas traduções e versões. Dito de outro modo, importa-me distinguir em que medida a identificação do gênero feminino e a (homo)sexualidade de Renée Vivien a impulsionaram a traduzir os poemas sáficos tal como ela o fez, acentudando a expressão poética lesboerótica.

Antes, porém, de apresentar as duas traduções/versões feitas por Renée Vivien e comentar brevemente a onipresença da inspiração sáfica na obra dessa autora - que parece ser pouco conhecia pelo público brasileiro ${ }^{2}-$, apresentarei um breve panorama que põe em relevo a excepcionalidade do trabalho de tradutora de Renée Vivien, sobretudo tendo em vista que, se muitas foram as traduções dos fragmentos de Safo para o francês, pouquíssimas foram aquelas feitas por mulheres.

\section{Tradutoras de Safo}

Examinando a lista "Cronologia da Presença de Safo na França", apresentada pela pesquisadora Joan DeJean na sua obra Fictions of Sappho, 1546-1937 (DEJEAN, 1989, p. 313-315), pode-se constatar que, até o ano de 1937, dentre os pouco mais de 40 homens a editarem e/ou 
traduzirem fragmentos de Safo, as únicas mulheres a intentá-lo foram Anne Dacier e Renée Vivien. Trata-se, respectivamente, das obras: Les poêsies d'Anacréon et de Sapho traduites de grec en françois, avec des remarques par Mademoiselle Le Fèvre (1681) - obra que teria, ainda durante o tempo de vida de sua autora, uma segunda edição, agora com o nome de casada da tradutora: "Mme Anne Dacier" (1699) -, e Sapho. Traduction nouvelle avec le texte grec (1903). Em 1966, uma terceira tradutora francesa, Édith Mora, lança uma nova tradução: Sappho. Histoire d'un poète et traduction intégrale de l'auvre.

A primeira dentre as supracitadas obras trata-se de uma publicação composta por cerca de 240 páginas que, em sua grande parte, como o próprio nome indica de forma explícita, são ocupadas por traduções e comentários sobre composições atribuídas a Anacreonte (VI-V a.C.). Apenas pouco mais de 20 páginas são dedicadas a Safo, compreendendo: uma parte dedicada à vida da poeta ("La vie de Sapho"), dois textos gregos de "Odes", acompanhados por suas traduções em prosa e comentários, ao que se segue, por fim, a apresentação de dois "Epigramas" atribuídos à poeta textos gregos acompanhados por suas respectivas traduções em francês. Vale destacar que tal trabalho teve uma boa recepção por parte da crítica da época (FABRE-SERRIS, 2016, p. 93).

Isto posto, vale ressaltar o fato de que Anne tomou como base da sua obra em questão a edição feita por seu pai, Tanneguy Le Fèvre, intitulada: Anacreontis et Sapphonis carmina. Notas et animadversiones additit Tanaquillus Faber, de 1660, que apresentava os textos gregos traduzidos para o latim. Destaco ainda que, apesar de as traduções de Anne Dacier não serem as primeiras traduções francesas das duas Odes sáficas presentes no livro da autora - visto que elas foram precedidas, entre outras, por aquelas presentes no volume: Les Odes amoureuses, charmantes et bachiques des poètes grecs Anacréon, Sappho et Théocrite (1670), de autoria de Du Four de la Crespelière -, elas foram as primeiras a terem uma mulher como tradutora e comentadora. $\mathrm{O}$ mesmo se dá, aliás, com relação às suas traduções da Ilíada (1699) e da Odisseia (1708).

Já Sapho. Traduction nouvelle avec le texte grec, de 1903, a segunda publicação de traduções de composições sáficas do grego para o francês assinada por uma mulher, traz traduções em prosa e/ou variações poéticas, de autoria da poeta Renée Vivien - nome de pluma de Pauline Mary $\operatorname{Tarn}^{3}$-, assim como reescrituras em outros idiomas, de autores como Catulo (I a.C.) e Charles Swinburne (1866). Volume que, como se poderia esperar, graças às descobertas de novos fragmentos da poeta, é bem mais extenso do que aquele apresentado por Mme. Dacier.

Com efeito, a obra de Renée Vivien é composta por cerca de 150 páginas organizadas em: prefácio ("Préface"), composto por quase cinco páginas, uma biografia de Safo ("Biographie de Psappha”), que ocupa seis páginas e, por fim, as traduções/variações poéticas. Estas últimas, por sua vez, encontram-se dispostas em três partes: a primeira, intitulada "Odes", traz 103 composições bastante fragmentadas; a segunda, "Épithalames", apresenta 13 composições e a terceira, "Fragments", apresenta passagens de textos de oito autores antigos. Ressalto ainda que essa obra, embora se trate da quarta publicação da autora, é a primeira na qual a marca do feminino do nome da mesma aparece explicitada, uma vez que nas demais sua assinatura aparecia assim abreviada: R. Vivien.

Como pontua Jacqueline Fabre-Serris, embora Sapho tenha sido em grande parte responsável por uma certa popularização do conhecimento dos fragmentos sáficos, nem por isso - e decerto pela 
ousadia de Renée Vivien no trato com o homoerotismo poético -, essa obra contou com a simpatia dos críticos da época. A reprovação é atestada mesmo anos depois, por André Billy, que no seu Époque 1900, de 1951, se refere à Renée Vivien como a "Sapho 1900, Sapho cent pour cent", ironizando a pretensão da autora em equiparar-se a Safo (BILLY Apud FABRE-SERRIS, 2016, p. 83).

A terceira e última obra a ser considerada: Sappho. Histoire d'un poète et traduction intégrale de l'auvre, de 1966, - publicada, portanto, no alvorecer da chamada "segunda onda" feminista na França - é composta por pouco mais de 460 páginas, dispostas em duas partes: "Essais", subdividida em seis capítulos e "Traductions". No ano seguinte à sua publicação, em 1967, ela foi agraciada com o Prix Broquette-Gonin de literatura, outorgado pela Academia Francesa. No entanto, como mostram de forma patente as apreciações relativas à mesma feitas por Hugh Lloyd-Jones e por Jean Carrière, em resenhas publicadas, respectivamente, na The Classical Review (1967) e na Revue des études anciennes (1968), ela faria objeto de árduas críticas (CARRIÈRE, 1966).

Com efeito, segundo os resenhistas, a obra peca, e muito, seja pela sua pretensão pouco factível em apresentar e traduzir na "íntegra" as fragmentárias composições da poeta de Lesbos, seja no tocante à qualidade das edições do texto grego nas quais se pauta e à tradução e comentários dedicados aos mesmos. Mas isso não é tudo: segundo Jean Carrière, as apreciações feitas por Édith Mora relativas a Safo e ao valor de sua obra perderiam em objetividade histórica, ao insistirem em uma reabilitação e glorificação da poeta àquela altura pouco úteis.

Se, de fato, Édith Mora faz jus a algumas das críticas da qual seu trabalho é objeto, não obstante, algumas dentre as considerações presentes nas supracitadas resenhas ironicamente confirmam a pertinência das acusações feitas por Mora, que não apenas aponta a crítica literária como um espaço marcado por misoginia, como também escancara a falsa objetividade acadêmica pretendida por muitos autores ao tratar de Safo e, em particular, do homoerotismo que pode ser lido em alguns dos fragmentos da autora.

Isto posto, e tendo em vista que o meu objetivo aqui não é tratar em detalhe de cada um dos trabalhos brevemente apresentados, antes de prosseguir, gostaria contudo de pontuar que a escolha de traduzir a poeta de Lesbos por parte das três tradutoras - ainda que de diferentes formas - , mostra-se atrelada à potência simbólica contida no ato de (re)colocar em cena uma voz poética que se expressa no feminino; voz tão antiga - e, portanto, imbuída de alguma autoridade -, quanto rara, e por isso cara a essas mulheres produzindo em contextos e domínios majoritariamente masculinos.

E, se no caso do último dentre esses trabalhos de tradução mencionados, o contexto de efervescência feminista e a posição assumida pela autora com relação a Safo - que ela descreve como "[...] a única voz feminina, a única percepção expressa por uma mulher que temos acerca de um mundo que conhecemos apenas por intermédio dos homens" (MORA, 1966, 10. Tradução livre do original francês) - deixam clara a pertinência política de sua escolha de tradução, ainda que dita de maneira menos afirmativa, tal pertinência de Safo como uma precusora pode ser igualmente lida em Anne Dacier, que faz questão de pontuar a qualidade de suas Odes. Qualidade essa que justificaria não apenas a boa reputação literária da autora, mas a sua transmissão e, claro, a sua tradução4.

Vejamos agora a amplitude e pertinência da onipresença sáfica na obra de Renée Vivien, uma vez que essa onipresença não só precede, como explica o seu trabalho de tradução, que parece ser uma espécie de prolongamento da sua própria experiência poética sáfica. 


\section{Ecos sáficos em Renée Vivien}

Muito embora Renée Vivien tenha falecido com apenas 32 anos, sua produção literária foi vasta. Autora de origem inglesa, ela no entanto produziu uma obra integralmente escrita em francês. Limitarei-me aqui a citar apenas as suas publicações que precederam Sapho (1903).

Seus poemas em verso foram inicialmente reunidos em duas coletâneas: Études et Préludes (1901) e Cendres et poussières (1902). A essas duas publicações seguiu-se aquela de uma coletânea de poemas em prosa intitulada Brumes de Fjords (1902) e outra de poemas em verso: Évocations (1903).

Em todas essas obras, a inspiração "sáfica" - no sentido amplo do termo: da poética de Safo como modelo de excelência literária ${ }^{5}$ e no sentido mais estrito de expressão poética homoerótica -, assim como a invocação nominal à poeta de Lesbos encontram-se ampla e abertamente presentes. Nesse sentido, reproduzo, a título de exemplo, o poema "À la Femme aimée", que abre a coletânea Études et Préludes, dedicada por Renée Vivien a "Á N......", isto é, à escritora estadunidense Natalie Clifford Barney (1876-1972), que foi sua companheira:

Lorsque tu viens, à pas réfléchis, dans la brume,

Le ciel mêlait aux ors le cristal et l'airain.

Ton corps se devinait, ondoiement incertain,

Plus souple que la vague et plus frais que l'écume.

Le soir d'été semblait un rêve oriental

De rose et de santal.

Je tremblais. De longs lys religieux et blêmes

Se mouraient dans tes mains, comme des cierges froids.

Leurs parfums expirants s'échappaient de tes doigts

En le souffle pâmée des angoisses suprêmes.

De tes clairs vêtements s'exhalaient tour à tour

L'agonie et l'amour.

Je sentis frissonner sur nies lèvres muettes

La douceur et l'effroi de ton premier baiser.

Sous tes pas, j'entendis des lyres se briser

En criant vers le ciel l'ennui fier des poètes.

Parmi des flots de sons languissamment décrus.

Blonde, tu m'apparus.

Et l'esprit assoiffé d'éternel, d'impossible,

D'infini, je voulus moduler largement

Un hymne de magie et d'émerveillement.

Mais la strophe monta bégayante et pénible,

Reflet naïf ; écho puéril, vol heurté,

Vers la Divinité. (VIVIEN, 2007). 
Nesse poema, o sujeito da enunciação, expresso em primeira pessoa, exprime com minúcias, e por intermédio de metáforas abundantes, os efeitos paradoxais, emocionais e físicos, suscitados pela percepção da aproximação daquela que inspira o poema: a "mulher amada" - sujeito cujo gênero é explicitamente feminino e que, evocado de antemão pelo título, é também o objeto a quem se destinam estes versos.

A coletânea Cendres et poussières, por sua vez, que Renée Vivien dedica "À mon amie H. L. C. B." (iniciais em desordem do nome de sua companheira: Hélène Betty Louise Caroline de Rothschild (1863-1947)), abre-se por um poema-invocação à poeta de Lesbos. Composição que não poderia ser mais eloquente quanto à importância dos motivos sáficos - manifesta pela presença de figuras tais como Éros e Afrodite e pela menção das tormentas que estes provocam, assim como pela evocação de objetos tais como a lira e as flores - e da própria Safo enquanto fonte de inspiração:

\section{Invocation}

Les yeux tournés sans fin vers les splendeurs éteintes,

Nous évoquons l'effroi, l'angoisse et le tourment

De tes baisers, plus doux que le miel d'hyacinthes,

Amante qui versas impérieusement,

Comme on verse le nard et le baume et la myrrhe,

Devant l'Aphrodita, Maîtresse de l'Éros,

L'orage et l'éclair de ta lyre,

Ô Psappha de Lesbôs!

Les siècles attentifs se penchent pour entendre

Les lambeaux de tes chants. Ton visage est pareil

$\grave{A}$ des roses d'hiver recouvertes de cendre,

Et ton lit nuptial ignore le soleil.

Ta chevelure ondoie au reflux des marées

Comme l'algue marine et les sombres coraux,

Et tes lèvres désespérées

Boivent la paix des eaux.

Que t'importe l'éloge éloquent des Poètes,

À Toi dont le front est las d'éternités?

Que t'importent l'écho des strophes inquiètes,

Les éblouissements et les sonorités?

La musique des flots a rempli ton oreille,

Ce remous de la mer qui murmure à ses morts

Des mots dont le rythme ensommeille

Tels de graves accords. 
Ô parfum de Paphôs ! ô Poète ! ô Prêtresse!

Apprends-nous le secret des divines douleurs,

Apprends-nous les soupirs, l'implacable caresse

Où pleure le plaisir, flétri parmi les fleurs!

Ô langueurs de Lesbôs! Charme de Mytilène!

Apprends-nous le vers d'or que ton râle étouffa,

De ton harmonieuse haleine

Inspire-nous, Psappha! (VIVIEN, 2007).

A presença da poeta de Lesbos seria outra vez renovada no poema em prosa que abre a segunda parte de Brumes de Fjords: "La Sirène Muette" - que narra, a seu modo, a morte de Safo decorrente do salto do rochedo de Lêucade ${ }^{6}$-, e também naquele que fecha esta coletânea: "La génèse Profane", no qual somos apresentados a uma "Psapphâ" inspirada por nada mais nada menos do que "Satan"”.

De forma ainda contundente, o poema de abertura da coletânea Évocations - também dedicada "À mon amie H. L. C. B." e publicada no mesmo ano de Sapho - não poderia ser mais emblemático quanto ao lugar de Safo como fonte de inspiração primeira e inesgotável:

Douceur de mes chants, allons vers Mytilène,

Voici que mon âme a repris son essor,

Nocturne et craintive ainsi qu'une phalène

Aux prunelles d'or.

Allons vers l'accueil des vierges adorées:

Nos yeux connaîtront les larmes des retours:

Nous verrons enfin s'éloigner les contrées

Des ternes amours.

L'ombre de Psappha, tissant les violettes

Et portant au front de fébriles pâleurs,

Sourira là-bas de ses lèvres muettes

Lasses de douleurs.

Là-bas gémira Gorgô la délaissée,

Là-bas fleuriront les paupières d'Atthis,

Qui garde en sa chair, savamment caressée,

L'ardeur de jadis.

Elles chanteront les Grâces solennelles,

Les sandales d'or de l'Aube au frais miroir,

Les roses d'une heure et les mers éternelles,

L'étoile du Soir. 
Nous verrons Timas, la vierge tant pleurée, Qui ne subit point les tourments de l'Êros, Et nous redirons à la terre enivrée L'hymne de Lesbôs. (VIVIEN, 1903a).

Apresentados estes poucos exemplos, é possível dizer, então, que a escolha de traduzir Safo seja em Renée Vivien nada mais do que um prolongamento e aprofundamento desse diálogo inter-poético que, desde o princípio da sua produção, ela procurou estabelecer com os fragmentos da poeta de Lesbos. Isto posto, vale contudo mencionar o fato nada anódino de que os ecos sáficos em Renée Vivien inspiram-se também em outra fonte indireta: a obra poética de Charles Baudelaire (1821-1867) - autor do qual ela fora leitora desde a juventude, e em cuja obra o safismo literário e a presença de Safo se fazem explicitamente presentes em pelo menos dois dentre os seis poemas condenados de As Flores do Mal (1857): "Lesbos" e "Mulheres malditas" (KASKOURA-SCHULZ, 2016).

Seja como for, fato é que, em Renée Vivien, a inspiração sáfica ganha mais espaço, aparecendo de forma definitivamente afirmada. Na perspectiva viviennienne - independentemente de toda a polêmica envolvendo essa leitura e da qual não pretendo tratar aqui - a poeta Safo fora definitivamente uma amante de mulheres, cujos versos expressaram de forma inequívoca uma voz homoerótica. Sendo assim, proponho aqui pensar que Renée Vivien se vale dos poemas e da figura de Safo não somente como fonte de inspiração, mas de autoridade, como forma de dar respaldo ao seu lugar de poeta e de amante de mulheres, cuja poesia dá lugar a um sujeito poético que expressa abertamente o desejo por outro sujeito/objeto de desejo, também ele marcado pelo gênero feminino.

Dizendo isso, não quero afirmar que Safo fora também ela "lésbica" - para tomar nossa noção moderna de orientação sexual -, tampouco que sua poesia expressa os seus próprios sentimentos. Chamo atenção, sim, para o que me parece ser a escolha estratégica de Renée Vivien: valer-se do reconhecimento com o qual a poética de Safo conta, como forma de se afirmar em um ambiente em grande medida hostil às mulheres escritoras e à expressão lesboerótica em seus escritos.

\section{Renée Vivientradutora}

Renée Vivien começou a ter aulas particulares de grego com Gaetan Baron no ano de 1898, ou seja, cerca de cinco anos antes da publicação da sua obra Sapho, e cerca de três anos antes da publicação de sua primeira coletânea. Temos conhecimento desse fato por intermédio de cartas escritas por Baron, conservadas graças a Salamon Reinach, historiador e arqueólogo francês (1858-1932), que no decorrer de sua vida colecionou referências relativas à Renée Vivien, considerada por ele "[...] como uma moça genial e a maior poeta do século XX" (FABRE-SERRIS, 2016, p. 93. Tradução livre do original francês). Esses documentos integram o acervo da Biblioteca Nacional da França desde 1932, mas, a pedido de S. Reinach, tornaram-se acessíveis para consulta apenas a partir do ano 2000 (FABRE-SERRIS, 2016, p. 94). Nas cartas escritas por 
Baron, encontramos referências não somente a esse fato, como também ao fato de que sua aluna Renée Vivien rapidamente progredira em seus estudos. Além disso, nas memórias manuscritas de Gaetan Baron, que também integram o fundo S. Reinach, o professor de grego observa: "[...] ao chamado de suas evocações, os fragmentos mais amorfos de Safo ganhavam de imediato forma e vida." (FABRE-SERRIS, 2016, p. 95. Tradução livre do original francês). Informações que reforçam a força do vínculo que, desde muito cedo, ligou a produção poética de Renée Vivien àquela de Safo de Lesbos. Sendo assim, e uma vez que já demos alguns exemplos dos ecos sáficos na poética de Renée Vivien que precederam à publicação de Sapho, passemos a considerar mais de perto esta obra.

Conforme já foi assinalado, as traduções e variações poéticas feitas por Renée Vivien, a partir dos fragmentos de Safo, além de precedidas por um prefácio o são por uma biografia de Safo. Nesse texto, a poeta de Lesbos é apresentada de forma inequívoca como uma amante de mulheres ${ }^{9}$. Renée Vivien não apenas não faz qualquer referência aos testemunhos antigos que atribuem a Safo um marido, e mesmo uma filha ${ }^{10}$, como nega veementemente que o desfecho da vida da poeta de Lesbos tenha se dado em Lêucade ${ }^{11}$.

Será, pois, orientada por essa leitura de uma Safo cuja poesia é lugar de expressão do seu desejo por aquelas que foram suas amantes, que Renée Vivien empreenderá as suas traduções/variações poéticas, dentre as quais comentaremos apenas duas que compõem a primeira parte de Sapho (“Odes"): "Ode à l'Aphrodita" e "Ode à une Femme aimée", duas das mais completas e comentadas dentre as composições de Safo às quais ora se tem acesso.

Começo pois, apresentando o texto grego que precede a tradução para o francês e a variação poética de Renée Vivien que abrem Sapho ${ }^{12}$ :

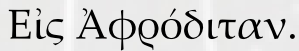

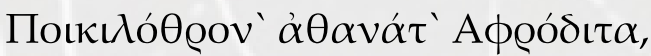

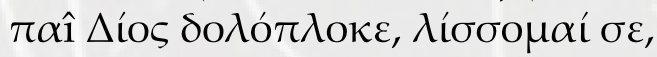

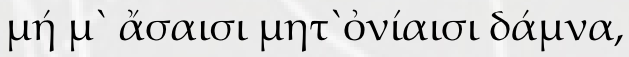
Tótvı $\alpha, \theta \tilde{v} \mu \mathrm{v}^{\circ}$

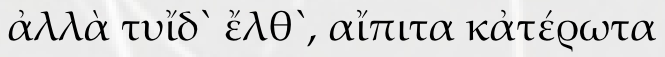

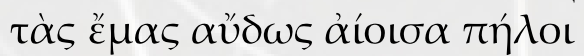

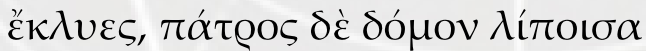

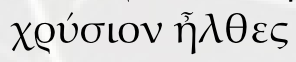

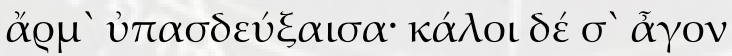

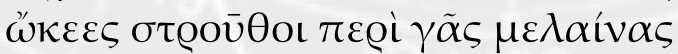

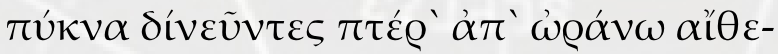

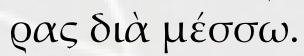




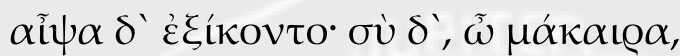

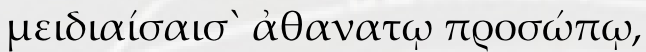

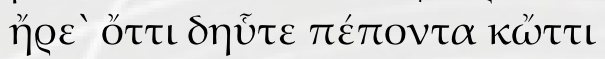

$\delta \eta \tilde{\tau} \tau \varepsilon \kappa \alpha ́ \lambda \eta \mu \mathrm{L}$,

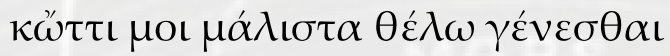

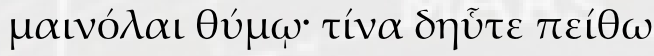

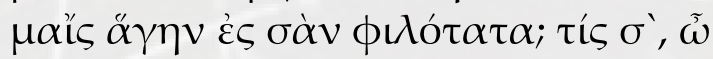

$\Psi \alpha \dot{\pi} \phi^{\prime}, \dot{\alpha} \delta \iota \kappa \eta ́ \varepsilon\llcorner;$

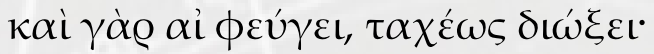

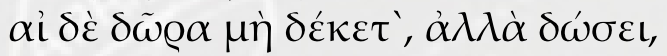

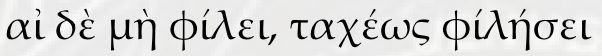

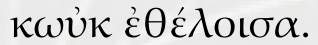

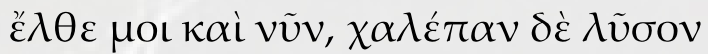
$\dot{\varepsilon} \kappa \mu \varepsilon \varrho i ́ \mu v \tilde{\alpha} v$, ő $\sigma \sigma \alpha \delta \varepsilon \dot{\varepsilon} \mu \mathrm{ol} \tau \dot{\varepsilon} \lambda \varepsilon \sigma \sigma \alpha \mathrm{t}$

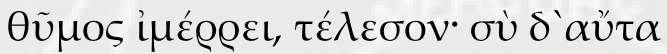

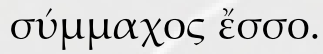

Em seguida reproduzo, na íntegra, a tradução em prosa e a versão em verso propostas por Renée Vivien ${ }^{13}$ :

Ode à l'Aphrodita

Toi dont le trône est d'en arc-en-ciel, immortelle Aphrodita, fille de Zeus, tisseuse de ruses, je te supplie de ne point dompter mon âme, ô Vénérable, par les angoisses et les détresses. Mais viens, si jamais, et plus d'une fois, entendant ma voix, tu l'as écoutée, et quittant la maison de ton père, tu es venue, ayant attelé ton char d'or. Et c'étaient des beaux passereaux rapides qui te conduisaient. Autour de la terre sombre ils battaient des ailes, descendus du ciel à travers l'éther. Ils arrivèrent aussitôt, et toi, $\hat{o}$ Bienheureuse, ayant souri de ton visage immortel, tu me demandas ce qui métait advenu, et quelle faveur j'implorais, et ce que je désirais de plus dans mon âme insensée. "Quelle persuasion veux-tu donc attirer vers ton amour? Qui te traite injustement, Psappha ? Car celle qui te fuit promptement te poursuivra, celle qui refuse tes présents t'en offrira, celle qui ne t'aime pas t'aimera promptement et même malgré elle. »Viens vers moi encore maintenant, et délivre-moi des cruels soucis, et tout ce qui mon cour veut accomplir, accomplis-le, et sois Toi-même mon alliée. 
Accueille immortelle Aphrodita, Déesse, Tisseuse de ruse à l'âme d'arc-en-ciel Le frémissement, l'orage et la détresse

De mon long appel.

J'ai longtemps rêvé : ne brise pas mon âme Parmi la stupeur et l'effroi de l'éveil, Blanche Bienheureuse aux paupières de flamme, Aux yeux de soleil.

Jadis, entendant ma triste voix lointaine, Tu vins l'écouter dans la paix des couchants

Où songe la mer, car ta faveur hautaine Couronne les chants.

Je vis le reflet de tes cheveux splendides Sur l'or de nuage et la pourpre des eaux Ton char attelé de colombes rapides

Et de passereaux.

Et le battement lumineux de leurs ailes Jetait des clartés sur le sombre univers, Qui resplendissait de lueurs d'asphodèles

Et de roux éclairs.

Déchaînant les pleurs et l'angoisse des rires, Tu quittas l'aurore immuable des cieux. Là-bas surgissait la tempête des lyres Aux sanglots joyeux.

Et toi, souriant de ton divin visage, Tu me demandas : "D'où vient l'anxiété A ton grave front, et quel désir ravage

Ton corps tourmenté?

«Qui te fait souffrir de l'âpre convoitise? Et quelle Peithô, plus blonde que le jour Aux cheveux d'argent, te trahit et méprise,

Psappha, ton amour? 
«Tu ne sauras plus les langueurs de l'attente.

Celle qui te fuit te suivra pas à pas.

Elle t'ouvrira, comme la Nuit ardente,

L'ombre de ses bras.

«Et tremblante ainsi qu'une esclave confuse,

Offrant des parfums, des présents et des pleurs,

Elle ira vers toi, la vierge qui refuse

Tes fruits et tes fleurs.

«Par un soir brûlant de rubis et d'opales

Elle te dira des mots las et brisés,

Et tu connaîtras ses lèvres nuptiales

Pâle de baisers.

Apresentados os textos, as observações que se seguem aqui limitam-se a contemplar, de modo conciso, um único aspecto: a sua maneira de traduzir o gênero do objeto do desejo não correspondido da evocadora, que se expressa em primeira pessoa e que aparece identificada no verso 20 pelo nome “ $\Psi \alpha ́ \pi \phi$ ” (Safo). Falta de reciprocidade essa que, ademais, trata-se justamente do assunto que motiva a presente reevocação da deusa Afrodite.

Começo observando que, no texto grego adotado por Renée Vivien, deve-se notar que o objeto do desejo daquela que evoca Afrodite, embora seja designado no verso 18 pelo neutro

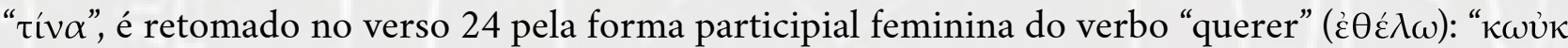
$\dot{\varepsilon} \theta \varepsilon ́ \lambda o เ \sigma \alpha " 14$. Ou seja, Renée Vivien (assim como o fez posteriormente Édith Mora) não hesitará em adotar lições nas quais o feminino é mantido não apenas no texto grego tomado como base, mas nas leituras e, consequentemente, na tradução e na variação que ela opta por fazer: de uma composição sáfica que expressa, de forma inequívoca, um homoerotismo no feminino. O que não somente retoma como reforça o homoerotismo explícito que se expressa ao longo de praticamente toda a sua própria poética, no âmbito da qual a evocação do nome da poeta de Lesbos se faz com frequência (VIVIEN, 2007); escolha abertamente simpática ao que hoje entendemos em termos de "lesboerotismo", e que se repete na tradução e versão dadas à composição que segue.

A transmissão dessa composição se deve, sobretudo, à sua citação no tratado Do Sublime (I d.C.) - tratado cuja datação e autoria, embora sujeitas a controvérsias, é normalmente creditada a (Pseudo)Longino -, sendo considerada ali como nada mais nada menos do que o modelo do sublime. Apreciação que justifica as centenas de traduções e variações poéticas que lhe foram dedicadas ao longo dos séculos (BRUNET, 1998), dentre as quais se encontram, entre outras, aquela de Catulo (I a.C.), que Renée Vivien apresenta logo depois da sua tradução e variação. Consideremos pois, o texto grego, para a seguir apresentar os textos de Vivien: 


\section{Eis 'E $\omega \mu \varepsilon^{\prime} v \alpha v$}

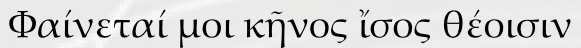

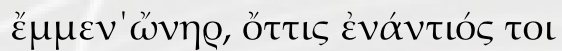

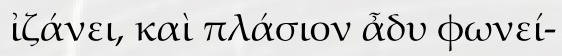

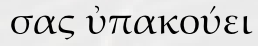

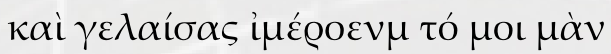

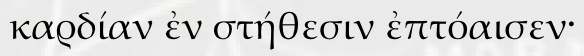

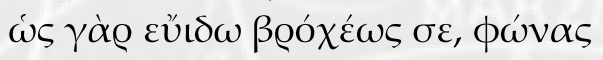

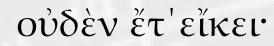

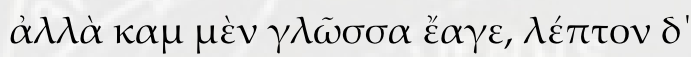

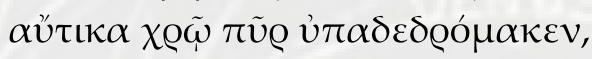

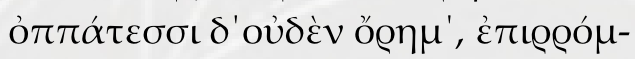

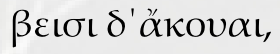

$\dot{\alpha} \delta \varepsilon \mu \grave{i} \delta \varrho \omega \varsigma \kappa \alpha \kappa \chi \varepsilon \dot{\varepsilon} \varepsilon \tau \alpha \mathrm{l}, \tau \varrho o ́ \mu \delta \dot{\varepsilon}$

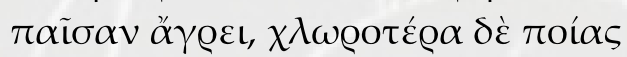

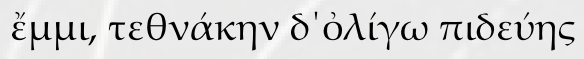
фaívo $\mu^{\prime} .$.

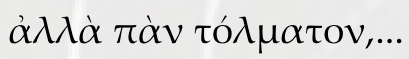

Ode à une Femme aimée

Il me paraît l'égal des Dieux, l'homme qui est assis dans ta présence et qui entend de près ton doux langage et ton rire désirable, qui font battre mon cœur au fond de ma poitrine. Car lorsque je t'aperçois, ne fût-ce qu'un instant, je n'ai plus de paroles, ma langue est brisée, et soudain un feu subtil court sous ma peau, mes yeux ne voient plus, mes oreilles bourdonnent, la sueur m'inonde et un tremblement m'agite toute; je suis plus pâle que l'herbe, et dans ma folie je semble presque une morte... Mais il faut oser tout...

L'homme fortuné qu'enivre ta présence

Me semble l'égal des Dieux, car il entend

Ruisseler ton rire et rêver ton silence,

Et moi, sanglotant,

Je frissonne toute, et ma langue est brisée Subtile, une flamme a traversé ma chair, Et ma sueur coule ainsi que la rosée Âpre de la mer ; 
Un bourdonnement remplit de bruits d'orage

Mes oreilles, car je sombre sous l'effort,

Plus pâle que l'herbe, et je vois ton visage

A travers la mort.

Temos aqui, novamente, a opção por uma tradução que, desde o título escolhido, denota a sua opção de dar a ler um texto no qual a voz poética, que se expressa em uma primeira pessoa marcada pelo gênero feminino ${ }^{15}$ - o que em francês é evidenciado pela vogal "- $e$ " ao final de duas palavras: "toute", "morte" -, descreve os efeitos provocados em todos os seus sentidos pela presença daquela a quem ela dedica a sua Ode: a mulher amada ("Femme aimée"). Título que ademais faz eco àquele que Renée Vivien dera ao poema de abertura da sua coletânea Études et Préludes: "À la Femme aimée”, apresentado anteriormente. Escolha bastante ousada se comparada, entre outras, àquela feita por Anne Dacier, que em sua tradução evita toda e qualquer marcação de gênero da voz que enuncia o poema, optando, além disso, por conferir ao poema o título mais pudico de "A son amie".

Sem dúvida tais escolhas renderam a Renée Vivien inúmeras críticas, visto que tal opção pode ser vista como defensora e enunciadora de um posicionamento "ideológico" supostamente ausente naqueles trabalhos que optam por uma tradução que procura apagar qualquer marca de homoerotismo da poética sáfica. No entanto, e sem procurar defender aqui uma leitura e uma tradução mais ou menos correta, que dê a ler de modo inquestionável uma "Safo lésbica" ou, ao contrário, "heterossexual", busquei no decorrer deste texto pleitear por um acolhimento dessa tradução, feita por uma poeta, que foi, ela mesma, amante de mulheres, não só pelas suas qualidades literárias, mas também pelo fato de que ela demonstra excepcional abertura para traduzir uma das evidências que de fato marcam a poética grega arcaica: a possibilidade de expressão do homoerotismo, seja ele expresso tanto no masculino quanto no feminino (CALAME, 1996, p. 83).

\section{notas}

1 Duzentos é mais ou menos o número de fragmentos trazidos hoje pelas edições mais respeitadas. Desses pouco mais de duzentos fragmentos evocados, o conteúdo de apenas um dentre eles é tido como completo. Nesse sentido, e apenas para se ter uma ideia do tamanho das perdas envolvidas, vale lembrar que aquela que seria a primeira edição antiga dos poemas de Safo, feita pelos Alexandrinos, e que remonta ao século III a.C., teria sido composta por 9 volumes. Dentre esses volumes, conjectura-se que o primeiro comportaria de 60 a 70 poemas - ou seja, cerca de $30-35 \%$ do que temos hoje.

2 Em uma pesquisa feita no banco de teses e dissertações da Capes, no dia 13 de outubro de 2017, ao procurar pelo termo "Renée Vivien", não encontrei nenhuma ocorrência do nome da autora.

3 No entanto, como observa Nicole Albert, vale lembrar que, em alguns textos escritos em parceria com sua companheira Hélène de Zuylen, ela usa o psedônimo Paule Riversdale. (ALBERT, 2009, p. 147, nota 5).

4 Neste sentido, podemos ler no texto que precede as traduções de Anne Dacier: "La bonne opinion qu'elle [Sappho] avait d'elle, n'était pas trop mal fondée, puisque deux de ses Odes restées seules depuis tant de 
temps, ont eu la force de soutenir toute sa réputation, de faire passer son nom d'âge en âge, et de l'imprimer dans des hommes d'une telle manière, que si désormais il ne vivait pas toujours, ce serait une chose encore plus étonnante que de ce qu'il est venu jusqu'à nous.” (DACIER, 1699, p. 251. Grafia do francês atualizada).

5 Renée Vivien escreve vários poemas no qual ela retoma a chamada "estrofe sáfica”, que é "[...] formada de três versos hendecassílados e um adônio ( $l=$ sílaba longa; $b=$ breve; $x=$ anceps, isto é, longa ou breve): $1,2,3$ $\left(\begin{array}{llll}l & b & l & x\end{array}\right)\left(\begin{array}{llll}l & b & b & l\end{array}\right)\left(\begin{array}{lll}b & l & l\end{array}\right) / 4\left(\begin{array}{llll}l & b & b & l\end{array} \mid l\right)$. Esse esquema, cujo núcleo é o coriambo $\left(\begin{array}{llll}l & b & l\end{array}\right)$, confere acentuada sonoridade à composição ao alternar bastante as sílabas longas breves [...].” (RAGUSA, 2005, p. 250, nota 24).

6 Esta narrativa, que é retomada por muitos autores (ver, entre outros, as Heroides XV, de Ovídio (I a.C.- I d.C.)), conta que Safo teria saltado para a morte pelo desespero do seu amor não correspondido por Faon. Note que ela será retomada aqui por Renée Vivien, sem fazer menção alguma ao nome de Faon.

7 Para um estudo clássico da presença de Satanás na literatura francesa ver MILNER, 2007 [1960].

8 No mesmo ano da publicação desta coletânea, Baudelaire foi condenado por atentado aos costumes e à moral, tendo cinco de seus poemas condenados: "Lesbos", "Mulheres malditas" [Delfina e Hipólita], "O Letes", "À que está sempre alegre”, "As joias” e "As metamorfoses do vampiro”. Nesse sentido, torna-se pertinente lembrar também que o título inicialmente cogitado por Baudelaire para sua obra fora Les Lesbiennes (As Lésbicas).

9 Em uma passagem dessa biografia de Safo, por Renée Vivien, pode-se ler: "En face de l'insondable nuit qui enveloppe cette mystérieuse beauté, nous ne pouvons que l'entrevoir, la deviner à travers les strophes et les vers que nous restent d'elle. Et nous n'y trouvons point le moindre frisson tendre de son être vers un homme. Ses parfums elle les a versés aux pieds délicats des Amantes, ses frémissements et ses pleurs, les vierges de Lesbôs furent seules à les recevoir." (VIVIEN, 1903b, p. X).

10 As duas mais extensas, embora breves, notas biográficas relativas à autora às quais se têm hoje acesso, encontram-se em um papiro datado entre os séculos II/III d.C (P. Oxy. 1800) e e em uma entrada de um léxico bizantino: a Suda, do IX/X d.C (Suda, ,107).

11 Na leitura de Renée Vivien “[...] Phaon n'est qu'un mythe créé par quelques écrivais d'après la tradition populaire” (VIVIEN, 1903b, p. IX).

12 Para todos os textos citados de Sapho, utilizo a 1a edição (VIVIEN, 1903b).

13 Na edição de Renée Vivien, sua tradução e variação será seguida por uma espécie de releitura poética dessa mesma composição de Safo, feita em língua inglesa por Charles Swinburne (1837-1909), Poems and Ballads, Sapphics.

14 Vale mencionar que a tradução feita por Anne Dacier opta por apresentar este objeto como sendo do gênero masculino. $\mathrm{O}$ que se faz sobremaneira possível graças à lição do texto grego que ela adota para o

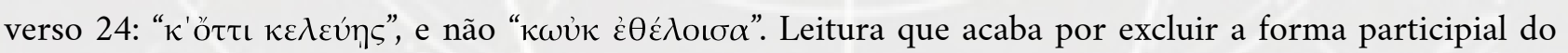
verbo "querer" - que aqui se encontra explicitamente no feminino -, que sustentaria uma leitura desse objeto amoroso como sendo também ele, tal como aquela que evoca Afrodite, um sujeito do gênero feminino.

$15 \mathrm{Na}$ edição do texto grego em VOIGT (1971) aparece a marca do feminino no pronome reconstituído “ $\alpha u ̛ \tau[\alpha$ ”, no verso 16 - “[...] e bem perto de estar morta / pareço eu mesma” (Tradução de Giuliana Ragusa para os versos 15 e 16 (RAGUSA, 2005 p. 269 )), - ausente no texto grego apresentado por Renée Vivien. 


\section{Referências}

ALBERT, N. G. "Renée Vivien d'un siècle à l'autre”. Diogène, Paris, v. 228, n. 4, p. 146-140, 2009. Disponível em: https://www.cairn.info/revue-diogene-2009-4-page-146.htm. Acesso: 13 out. 2017. BRUNET, P. L'égal de dieux. Cent versions d'un poème de Sappho. Paris: Allia, 1998.

CALAME, C. L'éros dans la Grèce Antique. Paris: Belin, 1996.

CARRIÈRE, Jean. "Edith Mora, Sappho. Histoire d'un poète et traduction intégrale de l'œuvre, 1966”. Revue des Études Anciennes, Bordeaux, t. 70, n.1-2, p. 153-155, 1968. Disponível em: http://www.persee.fr/doc/rea_0035-2004_1968_num_70_1_3815_t1_0153_0000_2. Acesso: 16 maio 2017.

DACIER, A. Les poésies d'Anacréon et de Sapho, traduites de grec en françois, avec des remarques par Madame Dacier. Nouvelle Édition augmentée de notes latines de Mr. Le Fèvre. Amsterdam: Paul Marret, 1699. Disponível em: https://books.google.com. Acesso: 15 maio 2017.

DEJEAN, J. Fictions of Sappho, 1546-1937. Chicago \& London: The University of Chicago Press, 1989.

DEMARCHI, C. Uma Safo à francesa: estudo das representações de Safo em imagens pictóricas da França do século XIX. 2013. 365f. Tese (doutorado) - Faculdade de Educação, Universidade Estadual de Campinas, Campinas, 2013. Disponível em: http://www.bibliotecadigital.unicamp.br/document/?code=000906096. Acesso: 26 mar. 2016. ÉCARNOT, C. L'écriture de Monique Wittig. À la couleur de Sappho. Paris: L'Harmattan, 2002.

FABRE-SERRIS, J. “Anne Dacier (1681), Renée Vivien (1903): Or What Does it mean for a Woman to Translate Sappho?” In: HALL, E.; WYLES, R. (eds.). Women Classical Scholars: Unsealing the Fountain from the Renaissance to Jacqueline de Romilly. Oxford: Oxford University Press, 2016. p. 78-102.

GREENE, E. (ed.). Reading Sappho: contemporary approaches. Berkeley: University of California Press, 1996.

GUBAR, Susan. “Sapphistries”. Signs, Chicago, v. 10, n. 1, p. 43-62, Autumn, 1984.

KASKOURA-SCHULZ, M. Sappho chez Baudelaire: pour une poésie à la croisée des arts. Sarrebruck: Éditions Universitaires européennes, 2016.

LLOYD-JONES, H. "Sappho's Poetry - Mora Édith: Sappho. Histoire du poète et traduction intégrale de l'œuvre. Pp. 462. Paris, Flammarion, 1966. Paper 30 F”. The Classical Review, Cambridge, v. 17, 3, p. 269-271, dez. 1967.

MARKS, E. "Lesbian Intertextuality”. In: MARKS, E.; STAMBOLIAN, G. (eds.). Homosexualities and French Literature. Ithaca and London: Cornell University Press, 1979. p. 353-377.

MILNER, M. Le diable dans la littérature française: de Cazotte à Baudelaire, 1772-1861. Paris, Éditions Corti, 2007 [1960].

MORA, É. Sappho. Histoire d'un poète et traduction intégrale de l'œuvre. Paris, Flammarion, 1966.

PRINS, Y. “Sappho's Afterlife in Translation”. In: GREENE, E. Re-reading Sappho: reception and transmission. Berkeley: University of California Press, 1996. p. 36-67.

RAGUSA, G. Fragmentos de uma deusa: a representação de Afrodite na lírica de Safo. Campinas: Editora da Unicamp, 2005. 
SKINNER, M. "Woman and language in ancient Greece, or, why is Sappho a woman?" In: RABINOWITZ, N.; RICHLIN, A. (eds.). Feminist theory and the classics. New York: Routledge, 1993. p. 125-142.

SNYDER, J. Lesbian desire in the lyrics of Sappho. New York: Columbia University Press, 1997.

VIVIEN, R. Brumes de Fjords. Paris: Alphonse Lemerre, 1902. Disponível em: http://gallica.bnf.fr. Acesso: 13 out. 2017.

VIVIEN, R. Évocations. Paris: Alphonse Lemerre, 1903a. Disponível em: http://gallica.bnf.fr. Acesso: 13 out. 2017.

VIVIEN, R. Sapho. Traduction nouvelle avec le texte grec. Paris: Alphonse Lemerre, 1903b. Disponível em: http://gallica.bnf.fr. Acesso: 18 maio 2017.

VIVIEN, R. Études et Préludes, Cendres et Poussières, Sapho. Aurillac: ErosOnyx, 2007.

VOIGT, E.-M. (éd.). Sappho et Alcaeus: fragmenta. Amsterdã: Athenaeum - Polak \& Van-Gennep, 1971.

WITTIG, M. Le corps lesbien. Paris: Les éditions de minuit, 2004 [1973].

WITTIG, M. Le point de vue, universel ou particulier. In: WITTIG, M. La pensée straight. Paris: Amsterdam, 2007 [1982], p. 89-95.

WITTIG, M.; ZEIG, S. Brouillon pour un dictionnaire des amantes. Paris: Grasset, 2001 [1976]. 